\title{
The Elaboration OF System OF THE Digital Pro- GRAMMEd CONTROL OF GRINding PROCESS ACCURACY
}

\author{
Huseynov Hasan \\ Azerbaijan Technical University, Azerbaijan, Baku av. H. Javid 25 \\ $\underline{\mathrm{tk} \_x t 2001 @ \text { mail.ru }}$
}

\begin{abstract}
The given article deals with the problems connected with the elaboration of system of the digital programmed control of grinding process accuracy which was used in the construction of information model of the basis of database systems. The idea of Technological primitive was used for the first time, in the limit of which the formation of systematically constant error occur in mechanical cutting. For formation of accuracy operation programs was used by means of synthesis of technological primitives of the conformity table. The correlation was installed between automated draft of technological operations and conduct of their accuracy. In the given automated system except operating conditions of cutting calculation of elastic deformations of technological systems, forecasting cutting accuracy, construction of cutting surface topography and determination the programs of operating process accuracy.
\end{abstract}

KEYWORDS: accuracy, mechanical cutting, technological primitive, conceptual plan, synthesis, database, operating program.

\section{INTRODUCTION}

One of the actual directions of increased process efficiency of mechanical cutting is the operation of their accuracy on the basis of database. We worked out 2 ways of increased process of mechanical cutting process.

- On the basis of hard program transmitters, by means of automated device.

- By means of numerical programmed conduct.

According to the first direction a number of program devices were worked out about flat grinding tools of circular and periphery of a circle to circular grinding tools of internal and external grinding. These devices were introduced into production with positive technical-economical effects in particular with four times accuracy increase of geometrical forms and reducing the main technological period in 1,8 times.

However, programmed devices with accuracy process of mechanical cutting on the basis of hard program transmitters like cams, firm cams etc. characteristic for the mainly for large-scale and mass production, where material and temporary expenditures connecting with elaboration and preparation of program transmitters are compensated for each specific operation. In an atmosphere of single and small- scale production, one of characteristic features is multi- nomenclature, equipment of each technological operation with individual program transmitters is impossible. Consequently, it becomes necessary to search more flexible programmed device with accuracy process, providing sharp cutting down tools and term preparation of operated programs. Actuality of these researches is also emphasized that specific gravity of individual and small-scale production in machine building is about $75 \%$, and tendency of its growth is expected according to economical transformations in industry.

The formulation of the question.

In single and small-scale production one of the main requirements to programmed devices is the equipment of their in variation to the mechanical cutting process of the certain field. From the above 
given facts, program provision of these devices must react efficiently to changes of nomenclature of products and reduction term- changes of their production. At the same time installation of program devices mustn't cause reduction of device universality and technological means of equipment. The development of microprocessor machinery and computer operated tools gives large opportunities in solving all these requirements and creates prerequisite for qualitative changes of functional opportunities of programmed devices. In this case the conditions are also created for implementation of correlation between automated project of technological operations and their conduct accuracy. This kind of correlation becomes possible except operating conditions of cutting, calculation of elastic deformations of technological systems is produced forecasting accuracy of cutting and construction topography of the cutting surface and as well as determination of program operated with accuracy process.

The elaboration of such system requires solving the main tasks as given below:

1. Elaboration of conducted linguistic provision for formal description of primary technological deformations and their input into computer system.

2. Elaboration of table word processors of technological provision systems, containing database about standard-type solutions and rules of their start.

3. Elaboration of methods formation of operated program. Forming algorithm provision systems, including algorithms of formation complete standard-type solutions and their calculation.

4. Optimization of process structure with precise time determination for function of programmed device.

\section{THEORETICAL REQUISITES}

For determination rules of construction of problem-orientated language system, it was necessary to produce hierarchy composition of technological process of mechanical cutting on the basis of technological unit of lower level. Composition must be held with calculation of methodological peculiarities of mathematical provision of systems to certain extent of concrete when behind the lowest expenditures of technological units appear concrete legality mechanizm of formation errors in cutting and through their achievements demanding accuracy. In traditional classification the lowest level of hierarchy composition of technological operations are passages. However, in implementation of more terminology methods of researches such classification is not enough. It demands deeper details of technological units breaking the passages straightly and opposite, as well as depending on the configuration of cutting surface to separate zones of technological primitives. By way of example analysing mechanizm of forming errors on flat grinding of periphery of a circular it was not difficult to be sure of that legality of forming errors of forms in every movement, but in some cases in the range of one movement it is different and expressed with separate mathematical models. On the basis of these reasons of technological discipline the idea of technological primitive was introduced for the first time. Formulating above given facts, a part of technological passage will be called technological primitive, in the range of which occurs formation of systematically current errors in mechanical cutting. In this case functional correlation between entrance and exit, operating and conducting parametres of process is introduced by single legality. Methodological agreement of mathematical and linguistic provision gives opportunities to unite them in systematicallyrelated range. This kind of correlation can be installed by direct analogy between morphological(geometrical) and functional descriptions of objects it means between technological primitives and mathematical models, characterized functional correlation of entrance, exit, operating and conducting parametres.

From this point of view conceptual plan of flat grinding process was worked out (Figure1) which was used in the construction of information model of database system DPOA. The difference of flat surface of high-accuracy machine details, ways and operating of flat grinding, form, size and characteristics of grinding circles determine a number of technological primitives. Operating system with process accuracy of flat grinding gives drawing up for each technological primitive appropriate mathematical mode[13-21]. On the basis of analysis of the given model necessary database is produced for operating process in the range of appropriate primitive. Flat grinding operation with periphery circle of firm surface of the gate 53M 001, direct bolt 3M65-350of gusher fittings is also introduced by way of example in the column of structural plan (Figure 2). Summits of the column express technological 
primitives, and edge sequence of their arrangement in the movement, of grinding process. The column consists of separate parts, introducing direct and reverse movements [14].

Preliminary analysis shows that in discussed conditions technological passage consists of 24 technological movements, from which 12 direct and 12 reverse movements. So, there are7 technological primitives in more complex movement.

For standardization and typing of technological primitives in the range of one method of grinding not depending on their arrangement in technological passage was produced their classification, in the frame of high accuracy plates which are used in oil industry mechanical engineering. As it is clear from the classificatory (Figure 3 and 4 ) each technological primitive double signed numerical code is attached to each technological primitive. For arrangement determination of technological primitive relatively other database elements they are in base rectangular right coordinate system and is introduced characteristic size determining their arrangement from coordinate axis.

Formulated description of technological primitives of concrete operation is produced on the basis of operated linguistics provision of the system. According to conceptual plan of d. atabase of technological primitive has the structure of 10 positional code. This code is synthesized with the help of codifications .The code structure consists of 3 parts: characteristics of technological operation, characteristics of technological passage and characteristics of technological primitive.

In appropriate conditions using equivalent mathematical models the database is equated with appropriate technological primitive. Accordingly, for adaptation of standard-type solution of concrete conditions of mechanical cutting down requires operation of accurate correlation between mathematical models of speed change part of a tool and complex conditions and their usage.

Operated linguistic provision of this system must be orientated for formulation and graphical information. It must have an ability for manipulation technological primitives in the process of formation of technological passages. For this purpose to the list of construction of language provision is included the means of generation technological unites with higher hierarchy level, scale, shift, turnings, composition, blending and removal.

\section{ARRANGEMENT OF THE TASK}

There are different forms of technological provision systems including standard-type solutions and rules of their acceptance. In technological project the more usage of it was found in processors table in the search of solutions, solutions table (one-side, double-side), algorithm table, correlation table, logical table of correlation and so on $[1,13]$.

The main demands to all these forms are:

-simplification database provision system;

-investigation of means for using standardized procedures of selection standard-type solutions for different tasks.

The analysis showed that more suitable forms of technological provision of given system is the formulation of operating accuracy program by synthesis of technological primitives, by means of correlation table. Grinding in symmetrical zones has the point for repetition of technological primitives and movements. Accordingly, it seems probable equating of the same technological primitives with some mathematical models. Besides, parameters, which use the models, don't depend on each other.

In accordance with the composition results, a number of standard-type solutions turned out of 43 mathematical models of speed change of the tool $[13,14]$. The meaning of technological primitive codes and mathematical models equating by them is included to the column a number of possible solutions of correlation table. (Table1)

The relation between technological passage, which is the lowest transit unit of grinding operation and standard-type local solutions in the form of technological primitives can be shown in the following way:

$$
\Pi_{\mathrm{K}}=\bigcap_{i=1}^{m} v_{k_{i}} ; \quad v_{k} \in V
$$

Here $v_{k^{-}}$standard-type local solution; $V$ - set of standard-type local solutions.

It is known that, every local standard-type solution has its usage conditions. Analyzing flat grinding operation, it will be determined the meaning of parameters influencing in the selection of local solutions. 
International Journal of Advances in Engineering \& Technology, April, 2020.

CIJAET

ISSN: 22311963

So, a number of possible solutions $V\left(v_{1}, v_{2}, \ldots v_{n}\right)$ and a number of possible conditions $\mathrm{X}_{i}=\left\{x_{i}\right\}, i=$ $1, \ldots, n$ determine the correlation table with the size of

$$
m=\sum_{k=1}^{m_{k}} \sum_{i_{k}=1}^{i_{k}} i_{k}
$$

Table 1.1. Primary correlation table $\mathrm{T}(\mathrm{X}, \mathrm{Y})$

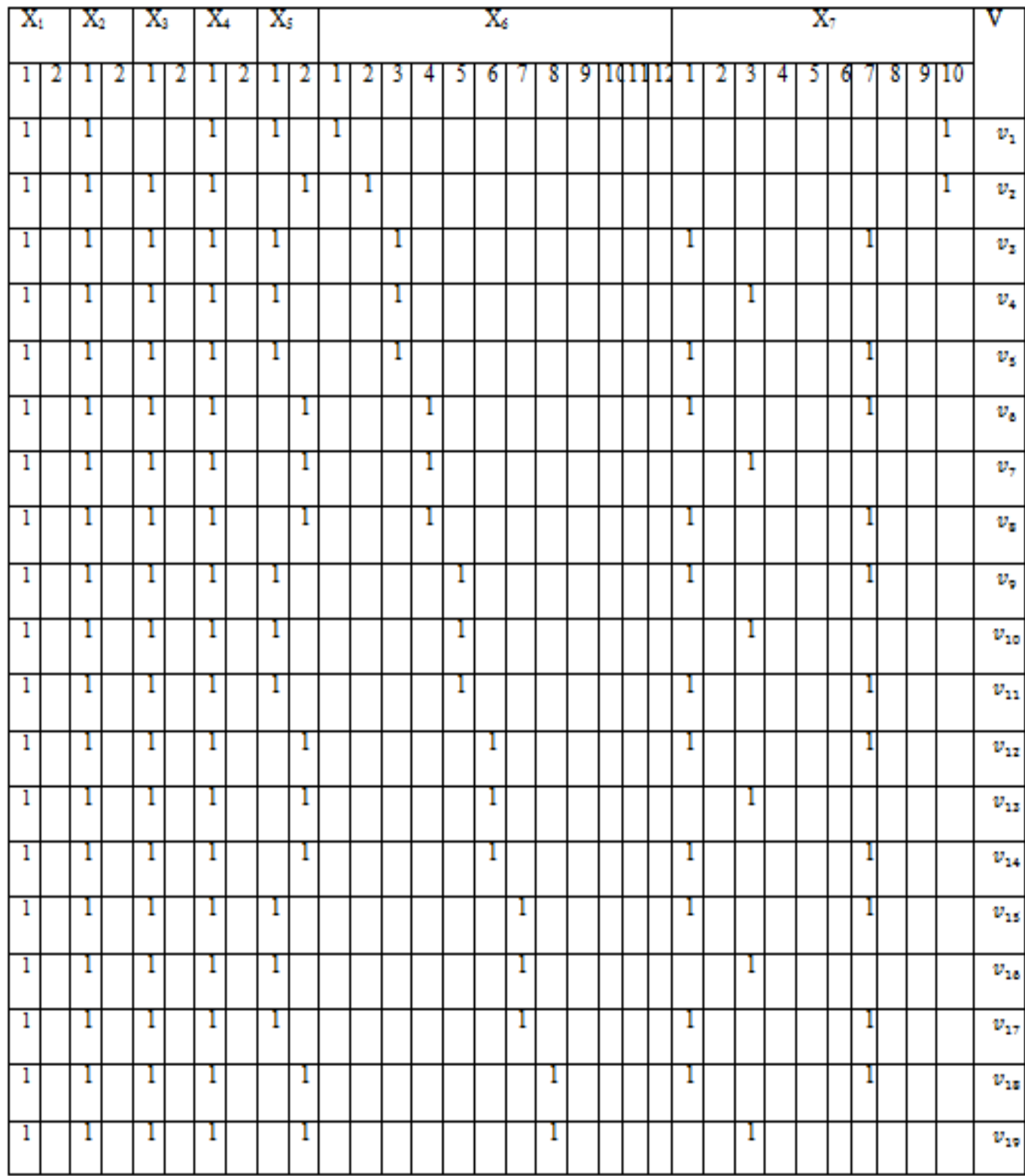

The continuation of table1.1 


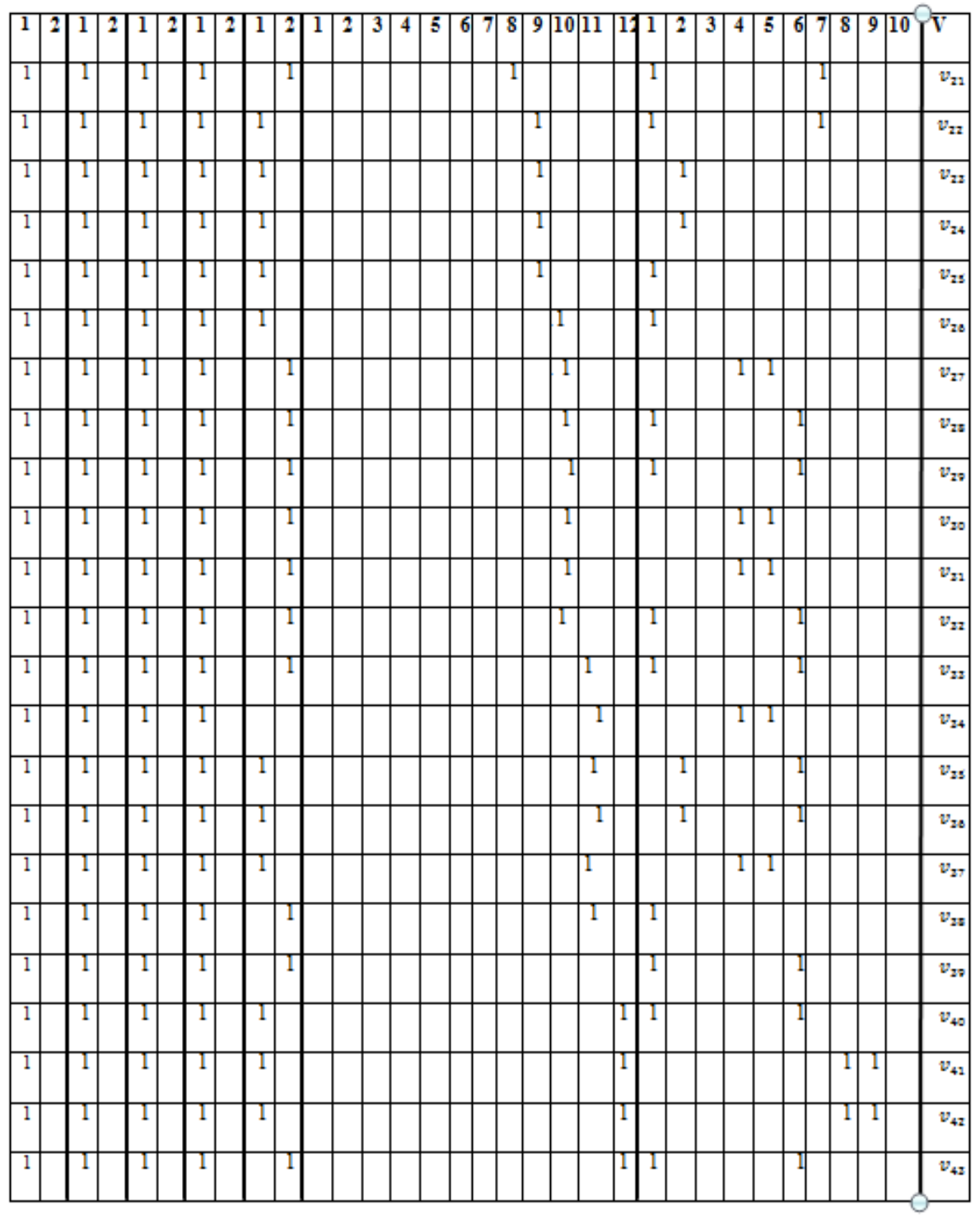

For each decision in appropriate square of the table if there is a solution in the given parameter it is filled in with one. As it is seen from the table meaning of parameters of the first 4 conditions of usage are either indifferent or indefinite. For standard-type solutions shown in table 1 the conditions of indefinite and indifference are determined from the following expressions [1]

$$
\begin{gathered}
R\left\{x_{k_{i_{k}}} ; T(X, V\}=\emptyset ; \quad\right. \text { (indefinite) } \\
R\left\{x_{k_{i_{k}}} ; T(X, V\}=V ; \quad\right. \text { (indifference) }
\end{gathered}
$$

In the given example of meaning of parameters $x_{11} ; x_{21} ; x_{31} ; x_{41}$ are indifferent, and the meaning of parameters $x_{12} ; x_{22} ; x_{32} ; x_{42}$ indefinite. Accordingly, parameters $x_{1} ; x_{2} ; x_{3}$ и $x_{4}$ are transit. The rest of parameters $x_{5} ; x_{6}$ и $x_{7}$ are dividers.

Consequently, removing all columns according to the meaning of indifferent parameter from the primary table, noting all equivalent meanings only to one parameter, we'll get normalized correlation table (Table 1.2).

Table 1.2. Normalized correlation table $T(X, V)$ 


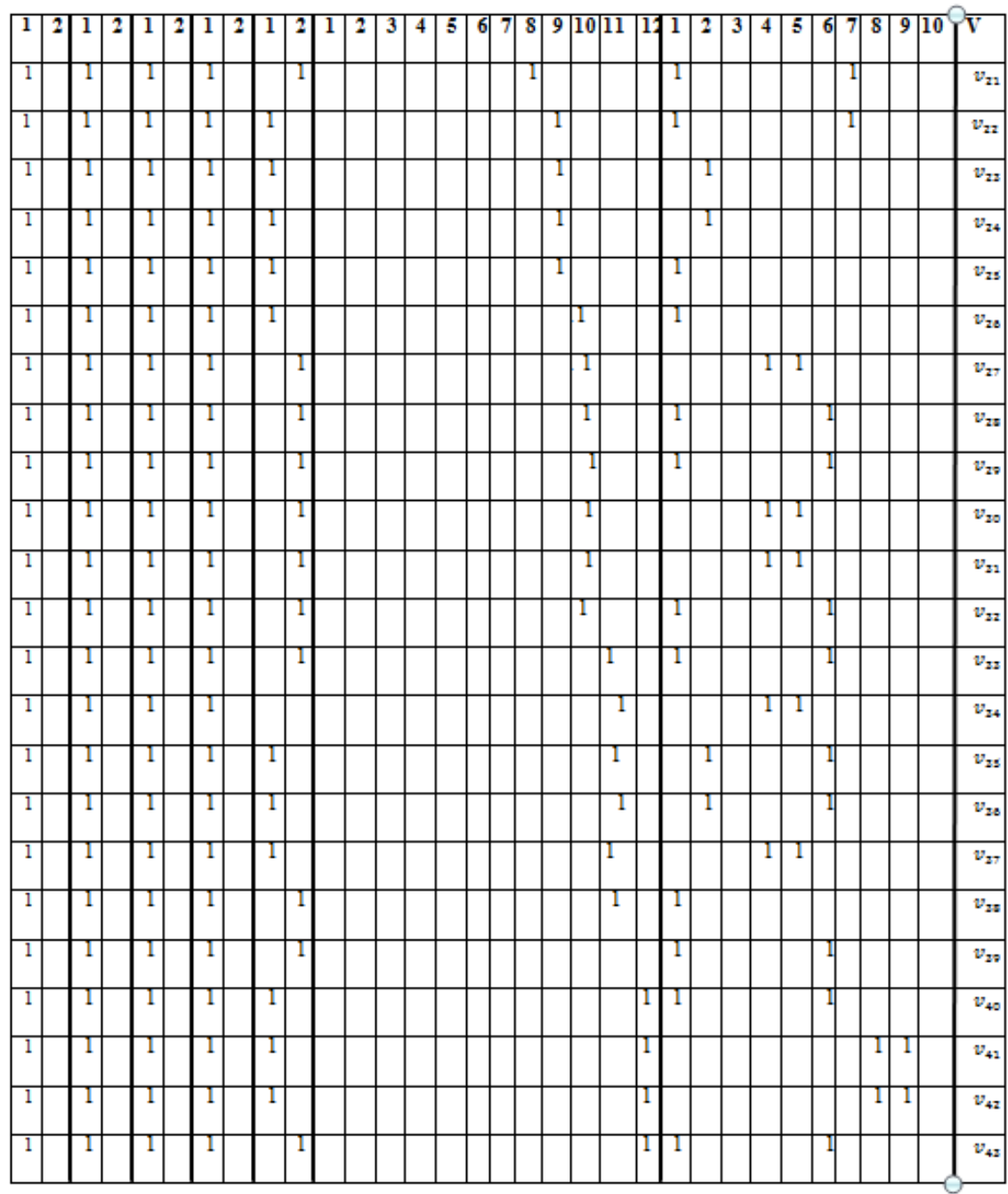

It is known that, more effective mathematical apparatus of primary correlation table analysis is the methods of column theory with the help of which minimized algorithms of column plan of choice solution is constructed and analyzed. Informative parameters will be determined for minimization of algorithms column plan [1].

$$
\rho\left\{x_{k} ; \quad T(X, V)\right\}=m_{k}+\rho_{k}-q_{k}
$$

where, $m_{k^{-}}$number of column parametersX $\mathrm{X}_{k} \in \mathrm{X}$-normalized correlation table; $\rho_{k}$-total number of solutions determining all equivalent significance parameters in pairs $\mathrm{X}_{k}$;

$q_{k^{-}}$parameter which takes the significance of zero or one depending on whether there is indefinite significanceX $\mathrm{X}_{k}$.

Informativity of parameters of normalized correlation table will be determined (Table 1.2)

$$
\begin{gathered}
\rho_{5}=2+43-0=45 \\
\rho_{6}=12+43-0=55 \\
\rho_{7}=10+40-0=50
\end{gathered}
$$

For parameters $x_{1} ; x_{2} ; x_{3}$ и $x_{4}$ informativity isn't taken into consideration since they are transits and don't divide multitude of solutions into subgroups, but they determine only in $x_{1} ; x_{2} ; x_{3}$ u $x_{4}$ equal to one can exist all multitude of solutions in $V$, in $x_{1} ; x_{2} ; x_{3}$ и $x_{4}$ equal to one the solution doesn't exist. According to the rules [3] for transit parameters of correlation table branches are put in the beginning of column. From the parameter dividers number for construction of column will be chosen the parameter with the fewer informativity $x_{3}$. 
For this we'll equate the beginning summit of column with all its size of correlation table $V=$ $\left\{v_{1}, v_{2}, \ldots, v_{43}\right\}$ and from it we'll get 2 columns (number of columns $x_{1}$ ). From each column with the significance of parameter will be equated in the given example (1 and 2). The end of column summits are equated with the multitude of solutions according to

And

$$
\left\{v_{1}, v_{3}, v_{4}, v_{5}, v_{9}, v_{10} v_{11}, v_{15}, v_{16}, v_{17}, v_{21}, v_{24}, v_{25}, v_{33}, v_{34}, v_{35}, v_{37}, v_{38}, v_{39}\right\}
$$

$$
\begin{gathered}
\left\{v_{2}, v_{6}, v_{7}, v_{8}, v_{12}, v_{13}, v_{14}, v_{18}, v_{19}, v_{20}, v_{32}, v_{40}, v_{41}, v_{43}\right\} . \\
\left\{v_{3}, v_{4}, v_{5}, v_{9}, v_{10} v_{11}, v_{15}, v_{16}, v_{17}, v_{21}, v_{24}, v_{25}, v_{33}, v_{34}, v_{35}, v_{37}, v_{38}, v_{39}\right\} \\
\text { и }\left\{v_{2}, v_{6}, v_{7}, v_{8}, v_{12}, v_{13}, v_{14}, v_{18}, v_{19}, v_{20}, v_{32}, v_{40}, v_{41}, v_{43}\right\} .
\end{gathered}
$$

We'll look through the end summits of constructed columns and for each of them separate tables will be constructed [1]. So, from the normalized table correlation parameters will be deleted for choosing the construction of the first column parameters $x_{1} ; x_{2} ; x_{3}, x_{4} u x_{5}$. From the rest parameters which are left on the correlation table $x_{6}, x_{7}$ we'll choose the lines for solution of representatives, equated with the end summit (in the given example it'll be the lines 1,3, 4,5,9,10,11,15,16,17,21, 22,24,25,33, 34, $35,37,38,30$ ) (Table 1.2). In the case of necessity, we'll produce normalization of partial table. Analogously we'll produce partial table for columns

$$
V=\left\{v_{2}, v_{6}, v_{7}, v_{12}, v_{13}, v_{14}, v_{18}, v_{19}, v_{20}, v_{26}, v_{27}, v_{28}, v_{30}, v_{31}, v_{32}, v_{40}, v_{41}, v_{43}\right\}
$$

For construction of the following branch will be chosen the parameter $\mathrm{X}_{6}$ which has the minimized informativity in normalized partial table

$$
\begin{aligned}
& \rho_{6}=12+20-6=26 \\
& \rho_{7}=10+20-0=30
\end{aligned}
$$

Constructed partial table for parameters $\bar{V}=\left\{v_{3}, v_{4}, v_{5}\right\}$ presented in Table 1.3. Analogously constructed partial tables for summits

$$
\begin{gathered}
\bar{V}=\left\{v_{3}, v_{4}, v_{5}\right\} ; \bar{V}=\left\{v_{15}, v_{16}, v_{17}\right\} ; \bar{V}=\left\{v_{21}, v_{22}, v_{24}, v_{25}\right\} ; \\
\bar{V}=\left\{v_{33}, v_{34}, v_{37}, v_{38}, v_{39}\right\} ; \quad \bar{V}=\left\{v_{6}, v_{7}, v_{8}\right\} ; \bar{V}=\left\{v_{18}, v_{19}, v_{20}\right\} ; \bar{V}=\left\{v_{12}, v_{13}, v_{14}\right\} ; \bar{V}= \\
\left\{v_{26}, v_{27}, v_{28}, v_{30}, v_{31}, v_{32}\right\} ; \quad \\
\bar{V}=\left\{v_{40}, v_{41}, v_{42}, v_{43}\right\}
\end{gathered}
$$

certain branches are added in the column plan.

On the basis of the minimized column plan (Figure 5) algorithm for choice of analytical subordinate of speed change of the tool for operating accuracy process of flat grinding of circular, is made analytical subordinate system mass (Table 1.4). For massive choice solution special program was worked out.

Table 1.3: Partial table for summits 
International Journal of Advances in Engineering \& Technology, April, 2020. OIJAET

ISSN: 22311963

$\left\{\bar{V}=v_{2}, v_{6}, v_{7}, v_{8}, v_{12}, ., v_{19}, v_{20}, v_{26}, v_{27}, v_{28}, v_{31}, v_{32}, v_{40}, v_{41}, v_{42}, v_{43}\right\}$

\begin{tabular}{|c|c|c|c|c|c|c|c|c|c|c|c|c|c|c|}
\hline \begin{tabular}{l|l}
1 & 2 \\
1
\end{tabular} & 2 & \begin{tabular}{l|l}
3 &
\end{tabular} & 4 & 6 & 7 & 8 & \begin{tabular}{|l|l|}
9 & 1 \\
\end{tabular} & \begin{tabular}{l|l|l|l}
10 & 11 & 12
\end{tabular} & \begin{tabular}{l|l|l|l}
1 & 7
\end{tabular} & \begin{tabular}{l|l}
2 & 6
\end{tabular} & \begin{tabular}{|l|l|}
4 & 5 \\
\end{tabular} & \begin{tabular}{|l|l|}
8 & 9
\end{tabular} & \begin{tabular}{|l|l|}
3 & 10 \\
\end{tabular} & V \\
\hline 1 & & & & & & & & & & & & & 1 & $v_{2}$ \\
\hline & & 1 & & & & & & & 1 & & & & & $v_{6}$ \\
\hline & & 1 & & & & & & & & & & & & $v_{7}$ \\
\hline & & 1 & & & & & & & 1 & & & & & $v$ \\
\hline & & & & & & & & & & & & & & \\
\hline & & & 1 & & & & & & 1 & & & & & $v_{12}$ \\
\hline & & & 1 & & & & & & 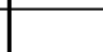 & & & & & $v_{13}$ \\
\hline & & & 1 & & & & & & 1 & & & & & $v_{14}$ \\
\hline & & & & & 1 & & & & 1 & & & & & $v_{13}$ \\
\hline & & & & & & & & & & & & & & \\
\hline & & & & & 1 & & & & - & & & & & $v_{19}$ \\
\hline & & & & & 1 & & & & 1 & & & & & $v_{20}$ \\
\hline & & & & & & & 1 & & 1 & & & & & $v_{26}$ \\
\hline & & & & & & & 1 & & & & 1 & & & $v_{27}$ \\
\hline & & & & & & & 1 & & & 1 & & & & $v_{3}$ \\
\hline & & & & & & & & & & & & & & \\
\hline & & & & & & & 1 & & & 1 & & & & $v_{30}$ \\
\hline & & & & & & & & 1 & & & 1 & & & $v_{31}$ \\
\hline & & & & & & & & 1 & 1 & & & & & $v_{32}$ \\
\hline & & & & & & & & 1 & 1 & & & & & $v_{40}$ \\
\hline & & & & & & & & & & & & & & \\
\hline & & & & & & & & 1 & & & & 1 & & $v_{41}$ \\
\hline & & & & & & & & 1 & & & & 1 & & $v_{42}$ \\
\hline & & & & & & & & 1 & 1 & & & & & $v_{43}$ \\
\hline
\end{tabular}


International Journal of Advances in Engineering \& Technology, April, 2020.

\section{Partial table for vertices}

$$
\bar{V}=\left\{v_{2}, v_{4}, v_{5}\right\} \quad \bar{v}=\left\{v_{2}, v_{4}, v_{5}\right\}
$$
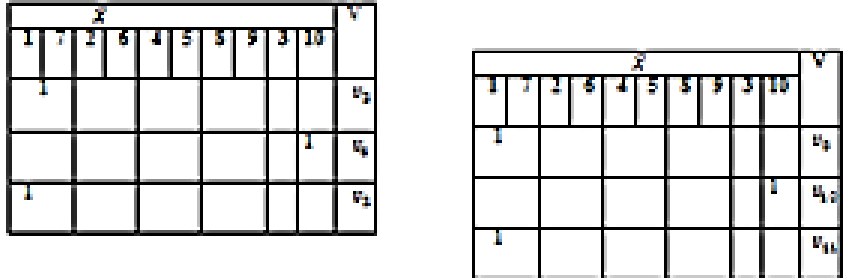

$$
\bar{V}=\left\{v_{2}, v_{3}, v_{s}\right\} \text { partial table for vertices } \bar{v}=\left\{v_{3}, v_{4}, v_{s}\right\}
$$

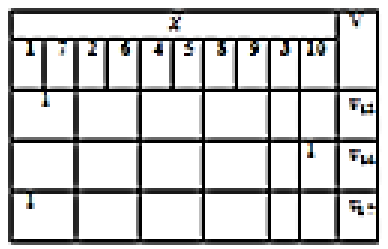

$$
\bar{V}=\left\{v_{32}, v_{34}, v_{25}, v_{37}, v_{32}, v_{20}\right\}
$$

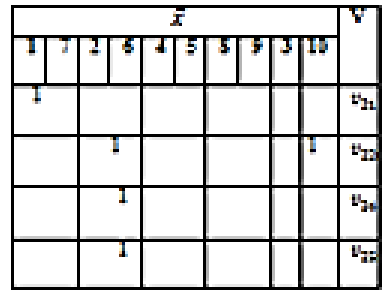

$$
\bar{V}=\left\{v_{v}, v_{7}, v_{7}\right\}
$$
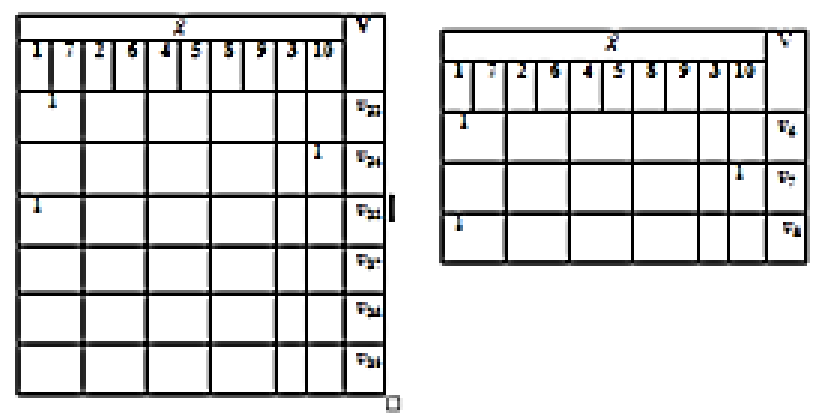
International Journal of Advances in Engineering \& Technology, April, 2020.

\section{Partial table for vertices}

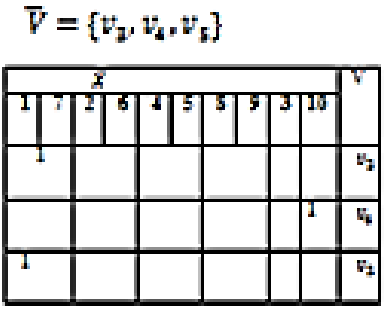

$$
\bar{v}=\left\{v_{2}, v_{4}, v_{5}\right\}
$$

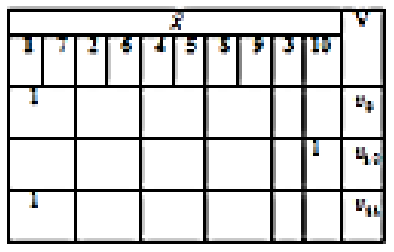

$$
\bar{V}=\left\{v_{2}, v_{3}, v_{s}\right\} \text { partial table for vertices } \bar{v}=\left\{v_{3}, v_{4}, v_{s}\right\}
$$

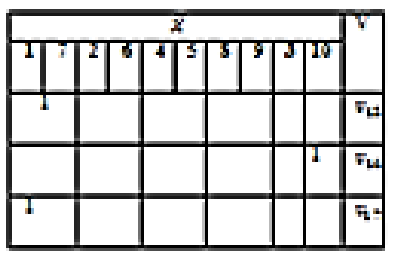

$$
\bar{V}=\left\{v_{22}, v_{34}, v_{35}, v_{37}, v_{32}, v_{20}\right\}
$$

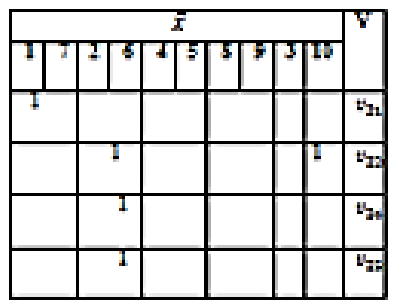

$$
\bar{V}=\left\{v_{6}, v_{7}, v_{4}\right\}
$$
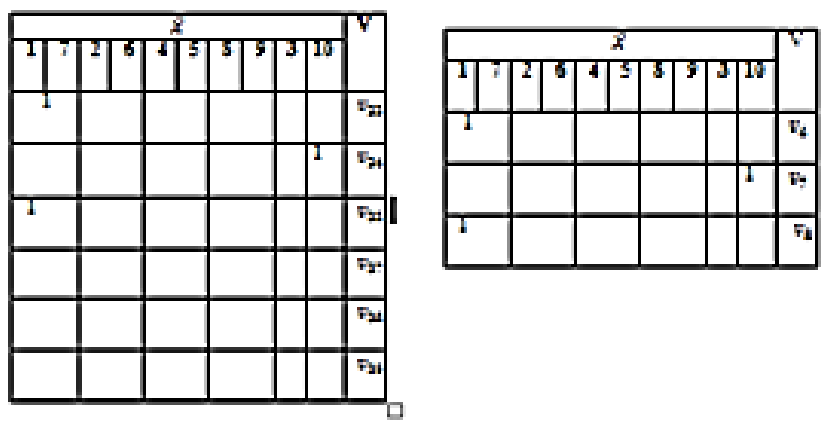

$$
\bar{V}=\left\{v_{18}, v_{10}, v_{20}\right\}
$$

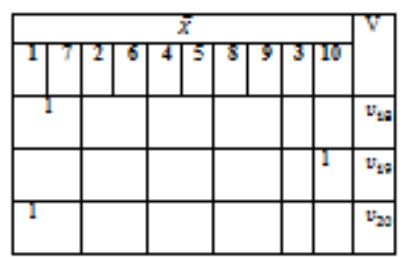

$$
\bar{V}=\left\{v_{26}, v_{27}, v_{28}, v_{30}, v_{31}, v_{32}\right\}
$$

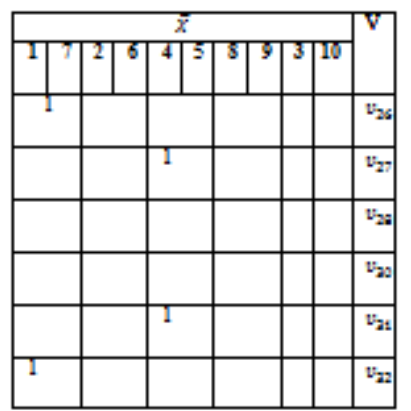

$$
\bar{V}=\left\{v_{12}, v_{13}, v_{14}\right\}
$$

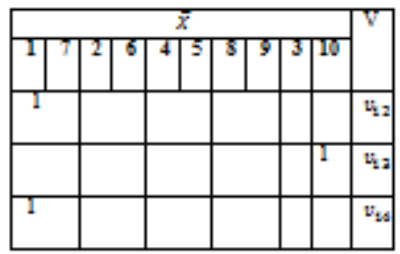

$$
\bar{V}=\left\{v_{40}, v_{41}, v_{42}, v_{43}\right\}
$$

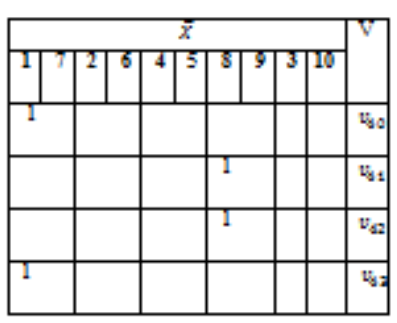


On the basis of the minimized column plan (Figure 5) algorithm for choice of analytical subordinate of speed change of the tool for operating accuracy process of flat grinding of circular, is made analytical subordinate system of massive. For massive choice solution special program was worked out.

Table 1.4: Massive of analytical subordinate system

\begin{tabular}{|c|c|c|c|c|c|c|c|}
\hline $\mathrm{X}_{5}$ & $\mathrm{X}_{6}$ & $\mathrm{X}_{7}$ & & $\mathrm{X}_{5}$ & $\mathrm{X}_{6}$ & $\mathrm{X}_{7}$ & \\
\hline 1 & 1,23 & 1 & $v_{1}$ & 1 & 9,15 & 1,7 & $v_{21}$ \\
\hline 1 & 2,22 & 2 & $v_{2}$ & 1 & 9,15 & 2,6 & $v_{22}$ \\
\hline 1 & 3,21 & 1,7 & $v_{3}$ & 1 & 9,15 & 2,6 & $v_{24}$ \\
\hline 1 & 3,21 & 3 & $v_{4}$ & 1 & 9,15 & 1,7 & $v_{25}$ \\
\hline 1 & 3,21 & 1,7 & $v_{5}$ & 2 & 10,14 & 1,7 & $v_{26}$ \\
\hline 2 & 4,20 & 1,7 & $v_{6}$ & 2 & 10,14 & 4,5 & $v_{27}$ \\
\hline 2 & 4,20 & 3 & $v_{7}$ & 2 & 10,14 & 2,6 & $v_{28}$ \\
\hline 2 & 4,20 & 1,7 & $v_{8}$ & 2 & 10,14 & $2,689,3,10$ & $v_{30}$ \\
\hline 1 & 5,19 & 1,7 & $v_{9}$ & 2 & 10,14 & 4,5 & $v_{31}$ \\
\hline 1 & 5,19 & 3 & $v_{10}$ & 2 & 10,14 & 1,7 & $v_{32}$ \\
\hline 1 & 5,19 & 1,7 & $v_{11}$ & 1 & 11,13 & 1,7 & $v_{33}$ \\
\hline 2 & 6,18 & 1,7 & $v_{12}$ & 1 & 11,13 & 4,5 & $v_{34}$ \\
\hline 2 & 6,18 & 3 & $v_{13}$ & 1 & 11,13 & 2,6 & $v_{35}$ \\
\hline 2 & 6,18 & 1,7 & $v_{14}$ & 1 & 11,13 & 2,6 & $v_{37}$ \\
\hline 1 & 7,17 & 1,7 & $v_{15}$ & 1 & 11,13 & 4,5 & $v_{38}$ \\
\hline 1 & 7,17 & 3 & $v_{16}$ & 1 & 11,13 & 1,7 & $v_{39}$ \\
\hline 1 & 7,17 & 1,7 & $v_{17}$ & 2 & 12 & 1,7 & $v_{40}$ \\
\hline 2 & 8,16 & 1,7 & $v_{18}$ & 2 & 12 & 8,9 & $v_{41}$ \\
\hline 2 & 8,16 & 3 & $v_{19}$ & 2 & 12 & 8,9 & $v_{42}$ \\
\hline 2 & 8,16 & 1,7 & $v_{20}$ & 2 & 12 & 1,7 & $v_{43}$ \\
\hline
\end{tabular}

Correlation table, written in the imprinted language, for computer input are presented in the following sequence [1]:

$$
\sum_{p=1}^{Z} T A_{p}\left\{\begin{array}{c}
x_{11} U x_{12} U x_{13} \ldots U x_{1 k}= \\
x_{21} U x_{22} U x_{23} \ldots U U_{2 k}= \\
x_{31} U x_{32} U x_{33} \ldots U x_{3 j}= \\
\ldots \ldots \ldots \ldots \ldots \ldots \ldots \ldots \\
x_{m 1} U x_{m 2} U x_{m 3} \ldots U x_{m n}=
\end{array}\right\}
$$

where, $x_{11}, x_{1 n} ; x_{21}, x_{22} ; x_{2 k} ; x_{m 1} ; x_{m 2} ; x_{m 1}$ argumentsofTC, which are according to usage conditions $x_{1}, x_{2}, x_{m}$, Z- solution number of TC, appropriate to $v_{1}, v_{2}, \ldots v_{n}$.

Primary information for solution search on the correlation table is the procession

$$
X=<\overline{x_{1}}, \overline{x_{2}}, \ldots, \overline{x_{n}}>
$$

For making procession, grinding surface is divided into elementary fields, which is then identified with technological primitives of classificator.

After entering the codes, the domens are gotten in the form of

$$
V=\left\{v_{j}\right\}, j=1,2, \ldots, m .
$$

The worked out program by means of which the correlation table is edited is the information-search system of automated preparation operating the program systems with the help of which database of digital program can be made with the grinding process accuracy. 


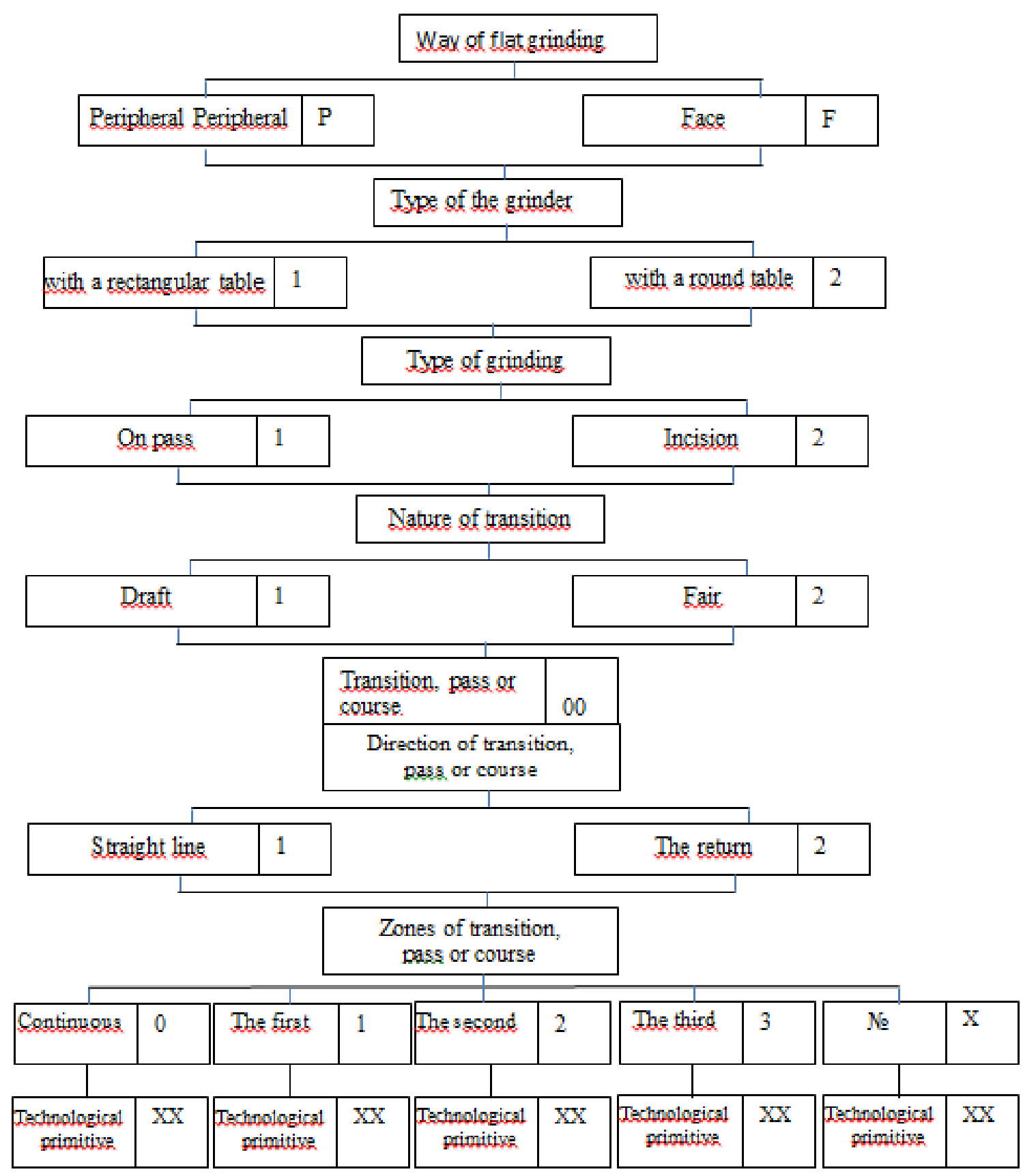

Figure1: Hierarchy plan of database of information model of flat grinding process 


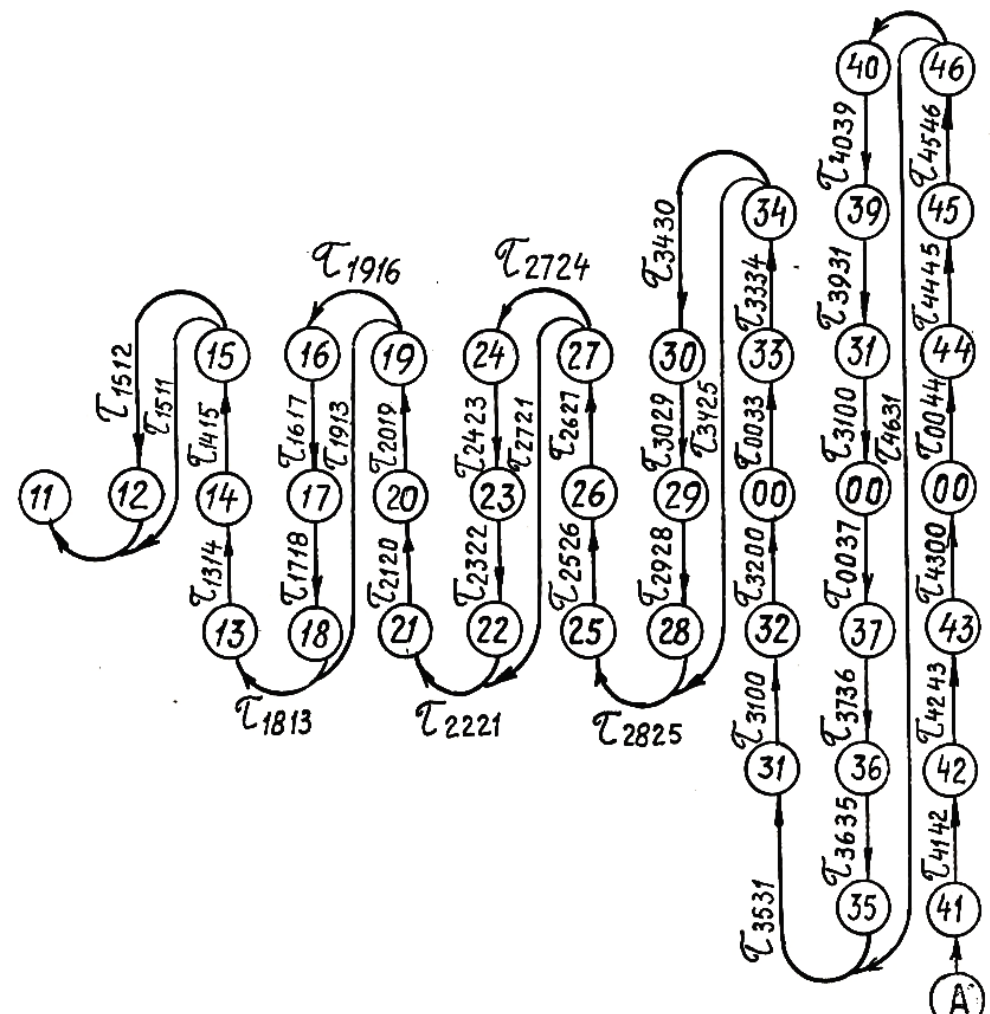

The continuation of the column

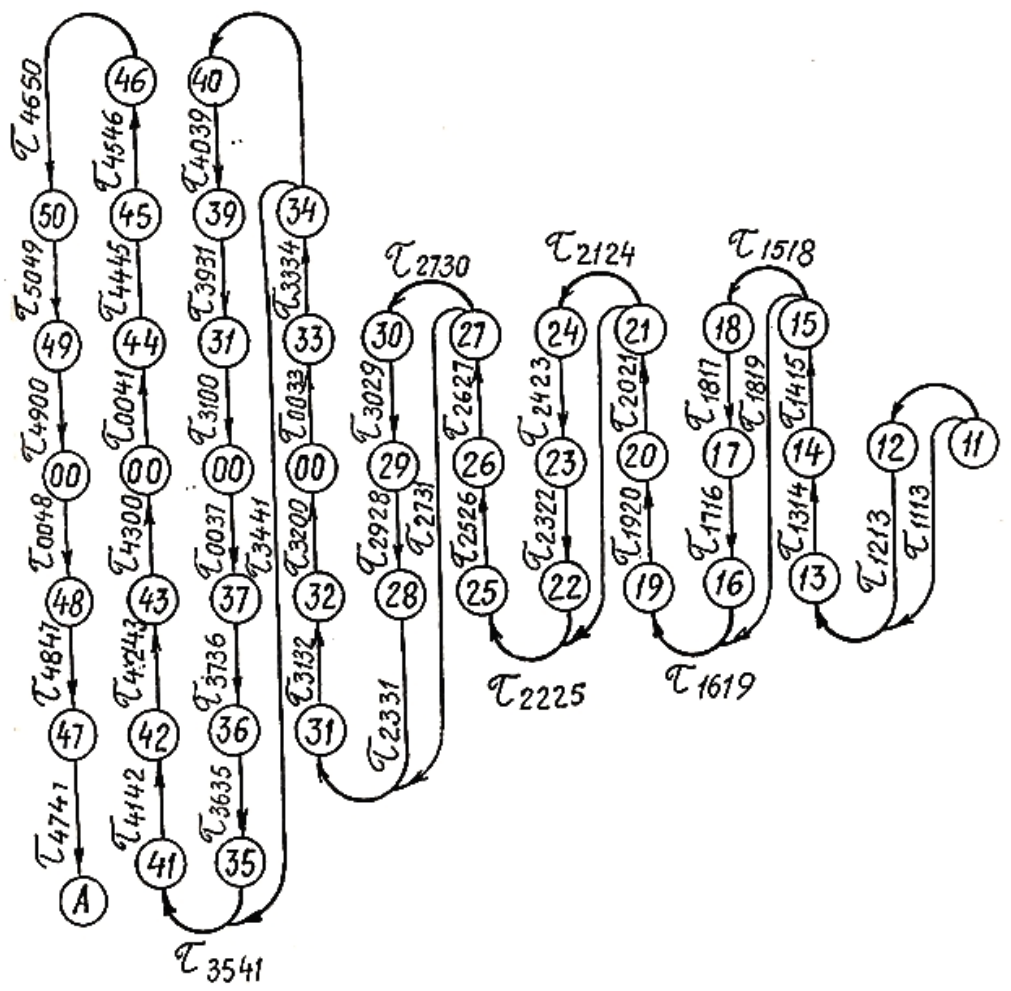

Figure 2: Column of technological passage operation of flat grinding with a circular of periphery 


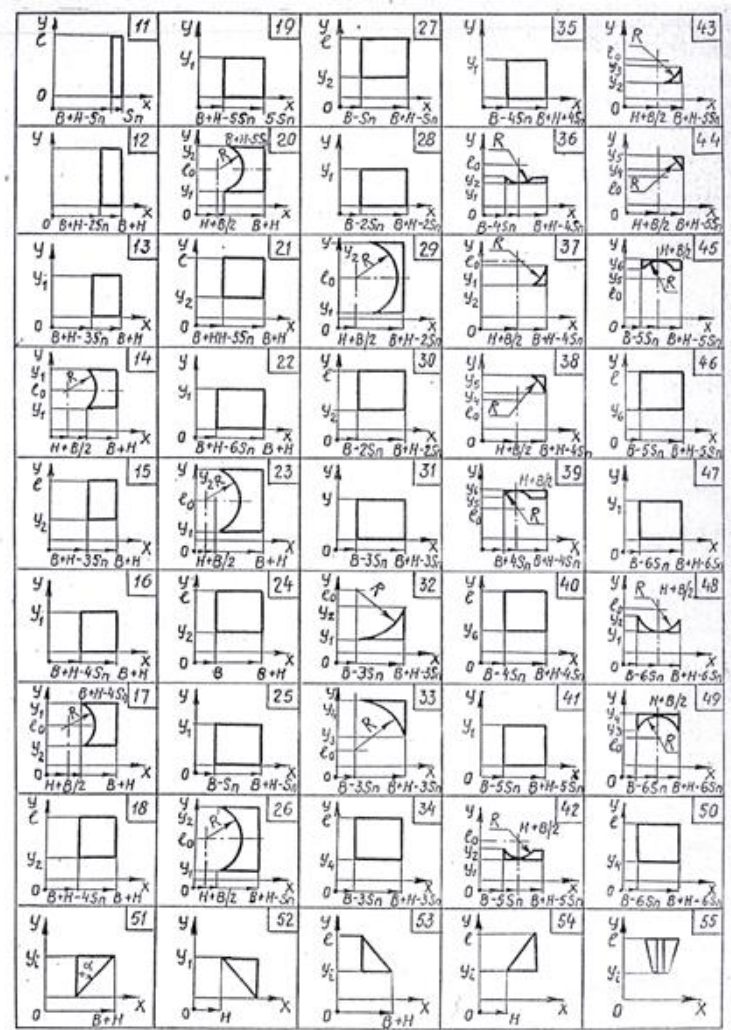

Figure 3: Catalogue of technological primitives in circular grinding

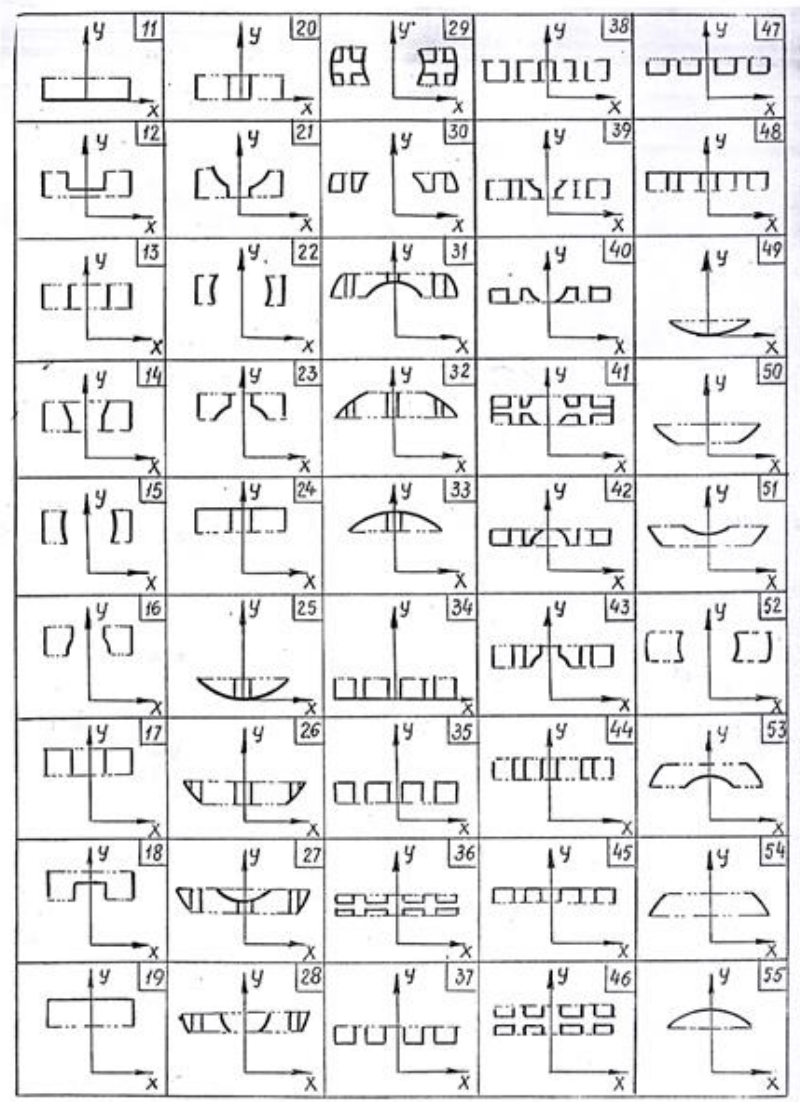

Figure 4: Catalogue of technological primitives in reverse grinding 
International Journal of Advances in Engineering \& Technology, April, 2020.

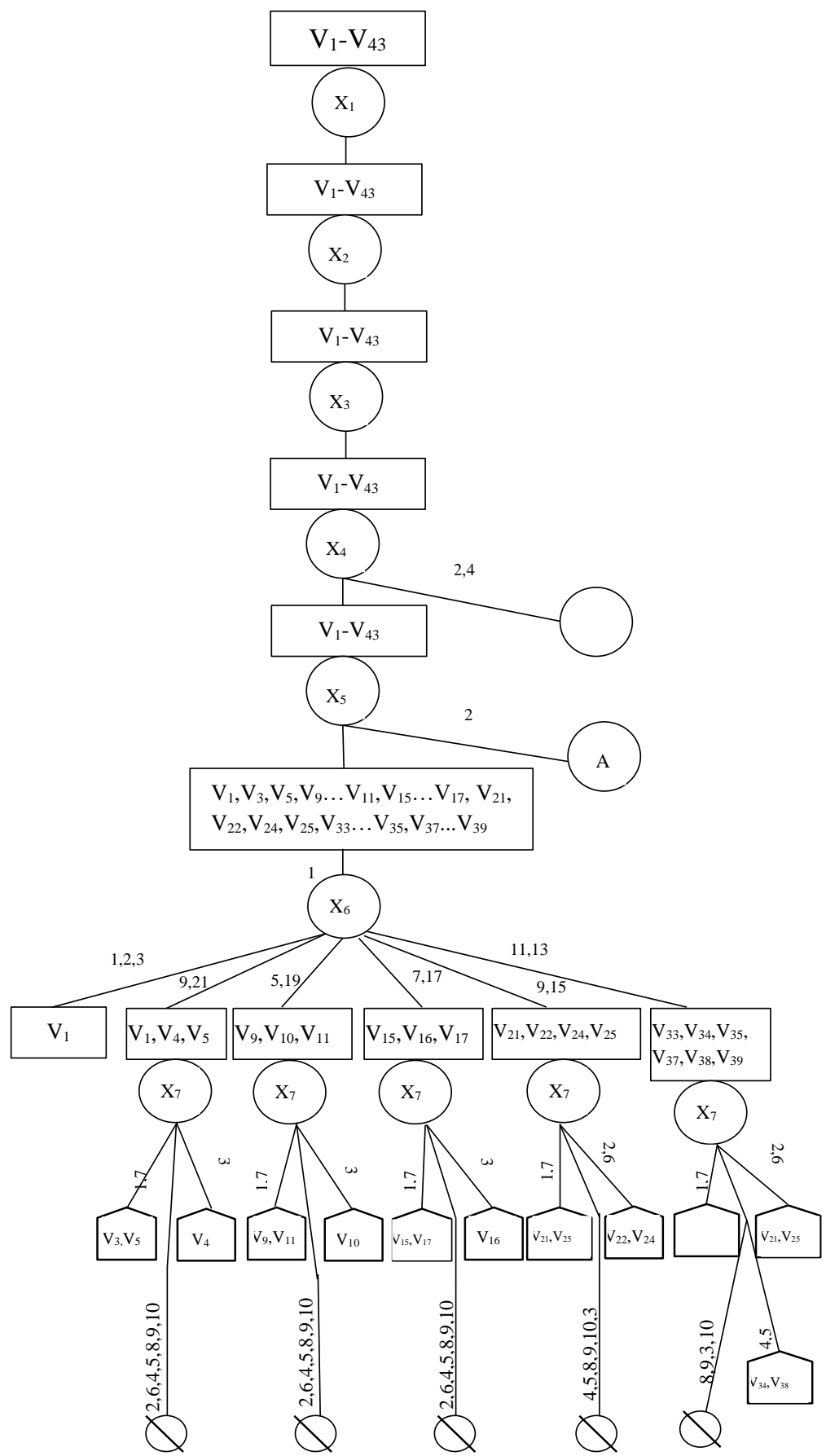


The continuation of Figure 5.

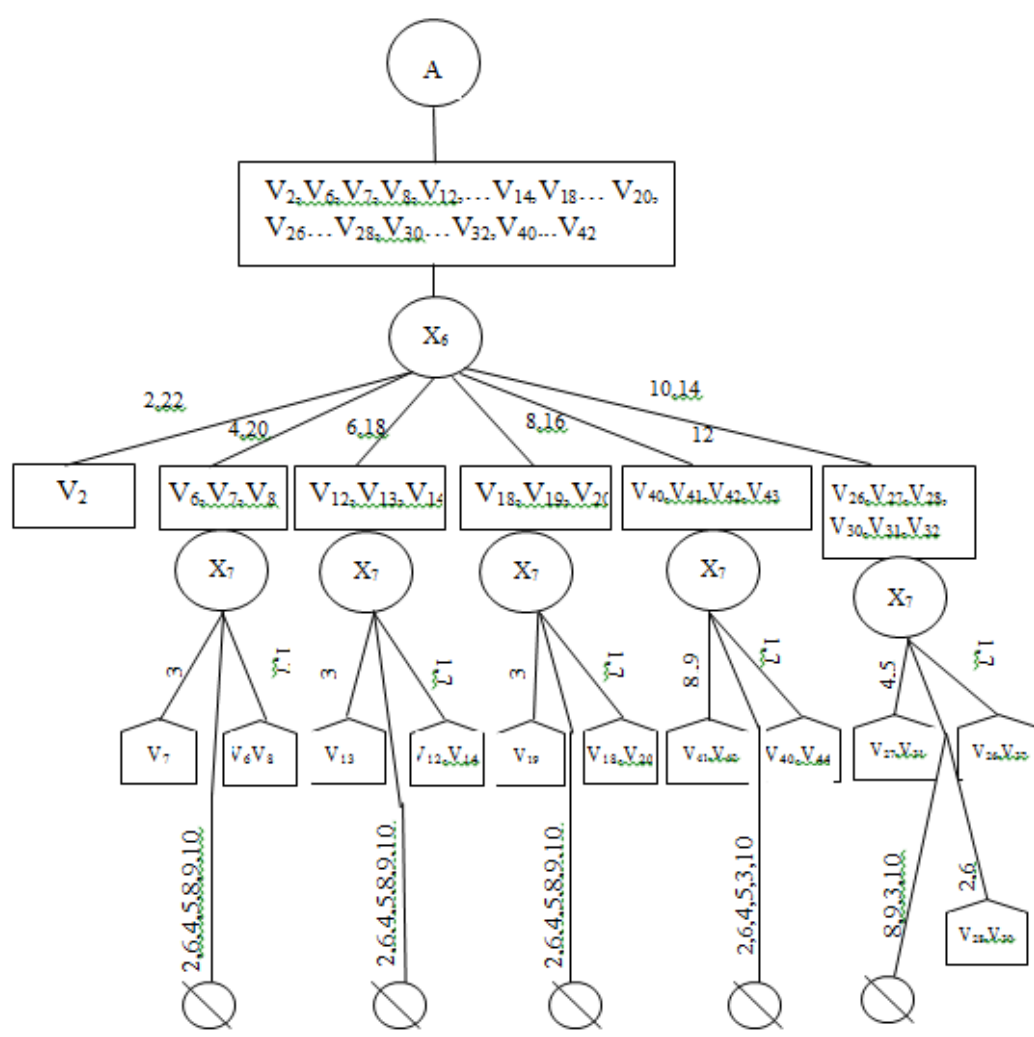

Figure 5: Minimized column -plan of algorithm for solutions choice from the correlation Table 1.4

\section{CONCLUSION}

1. Program operation with the mechanical cutting accuracy on the basis of hard program transmitters like cams, characteristic basically for large-scale and mass production, where material and time expenditures related with the elaboration and preparation of program transmitters are covered for each certain operation

2. In the condition of single and small-scale production, one of the characteristic features which is the multi-nomenclature, the equipment of each technological operation with individual program transmitter is impossible

3. The idea of Technological primitive», was used for the first time which is the end part of technological passage, in the range of which the formation of systematically constant errors occur in the mechanical cutting. In this case the functional relation between entrance and exit operating conditions of process is expressed by the one legality

4. On the basis of standardization and standard-type of plates used in oil-processing mechanical engineering was worked out the catalogue of technological primitives for every method of flat grinding

5. The conceptual plan of flat grinding process was worked out on the basis of information model of database system

6. More accepted form of technological provision of database was installed and it is the synthesis of technological primitive by means of correlation table

7. Information-search system of automated preparation of operated digital program was worked out with the accuracy on the basis of intellectual information.

\section{REFERENCES}

[1]. Automated systems of technological preparation of production in Engineering. /Under the editorship of G. K. Goransky. M. Mashinostroyeniye, 1976.240 pages. 
[2]. Baragetti S, Tordini F (2011) Experimental and Numerical Study of Shot Peened Thin Hard-Coated Components. Mechanics Based Design of Structures and Machines 39:441-460. doi: 10.1080/15397734.2011.569294

[3]. BSIa (British Standards Institute) BS 2007:1983 Specification for circular gear shaving cutters, 1 to 8 metric module, accuracy requirements

[4]. BSIb (British Standards Institute) BS 2518 Pt - 1:1983 Specification for rotary form relieved gear cutters - Diametral pitch

[5]. BSIc (British Standards Institute) BS 2518 Pt - 2:1983 Specification for rotary relieved gear cutters Metric module

[6]. BSId (British Standards Institute) BS 2697:1976 Specification for rack type gear cutters

[7]. BSIe (British Standards Institute) BS 3027:1968 Specification for dimensions of worm gear units

[8]. BSIf (British Standards Institute) BS 978 Pt - 4:1965 Specification for fine pitch gears - Hobs and cutters

[9]. Behzad M, Bastami AR, Mba DA (2011) New Model for Estimating Vibrations Generated in the Defective Rolling Element Bearings. Journal of Vibration and Acoustics 133: 41-49. doi:10.1115/1.4003595

[10]. Childs RTHC, Arola D (2011) Machining of cortical bone: simulations of chip formation mechanics using metal machining models. Machining Science and Technology 15: 206- 230. doi: 10.1080/10910344.2011.580699

[11]. Fan SKS, Chang JM (2009) A parallel particle swarm optimization algorithm for multi-objective optimization problems. Engineering Optimization 41:673-697. doi:10.1080/03052150902752058

[12]. Hloch S, Valicek J (2012) Topographical anomaly on surfaces created by abrasive waterjet. International Journal of Advanced Manufacturing Technology 59:593-604. doi: 10.1007/s00170-011-3511-3

[13]. Husseinov H.A (2000) Program control like machine processing. Baku. Chashioqli., p. 281

[14]. Husseinov H.A. Modeling and management of grinding process accuracy. Lambert.2016.p.298

[15]. Hassan Huseynov, Sahib Bagirov. Main features of the mechanizm of formation the surface grinding with the periphery of a straight disk. International Journal of Advances in Engineering end Technology. Vol.7Issue1,pp.66-74

[16]. Hassan Husseynov, Sahib Bagirov. The Analyses of the joint characreristics, based on the processing/ Methods of the contacting surfaces. International Journal of Advances in Engineering end Technology. Vol.7Issue2,pp.318-326

[17]. Hassan Husseynov, Sahib Bagirov.Tunzala Imanova. Methodical Features of developement of software for control of precision of the grindingmachines. Ingenieurtag2014, ingenieurwissenschaften und informatik der BrandenburgischenTechnischenUniversitat Cottbus-Senftenberg auf dem Campus Senftenberg am 2014.pp.7-8.

[18]. Husseinov Hassan Ahmad, Bagirov Sahib Abbas, RadoslavKrehel and Marek Kociško.The increased production efficiency and optimization terms of stationarity by flat grinding with abrasive circle surface," by. Advancede in Material Science and Technoloji. 108797

[19]. Husseinov H. A., Bagirov S. A. Raznozernisty grinding wheel//Messenger mashinostroyeniya.2008, No. 9, page 56-

[20]. Husseinov H.A., Mamedov Ch. M. A.NewDesign for End Grinding Wheels.Russian Engineering Research,2011, Vol.31,№1,p.37-40.

[21]. Husseinov H.A.,Bagirov S.A. Surfaces Ground by Standard Wheels and Wheels with Graduated Grain Seizes.Russian Engineering Research,2012.c.50-54.

[22]. Katsev P. G. Statistical methods a research of the cutting tool. M.: Mechanical engineering, 1974, 239 pages.

[23]. Kai AJ, Hansen JS, Martins JA (2009) Structural topology optimization for multiple load cases using a dynamic aggregation technique. Engineering Optimization 41:1103-1118. doi:10.1080/03052150902926827

[24]. Kountanya KR (2011) Surface finish and tool wear characterization in hard turning using a mathematical cutting tool representation. Machining Science and Technology 15:429-452. doi: 10.1080/10910344.2011.620916

[25]. Kilundu B, Chiementin X, Dehombreux P (2011) Singular Spectrum Analysis for Bearing Defect Detection. Journal of Vibration and Acoustics 133:51-58. doi:10.1115/1.4003938

[26]. Reznikov A.N. (1977) Abrasive and uncut diamond processing of materials. Machinery construction, 391.p. 4. Loading automation of round grinding machine with N.P.C.p.42

[27]. Ritto TG, Lopezb RH, Sampaioa R, Souza de Cursib JE (2011) Robust optimization of a flexible rotorbearing system using the Campbell diagram. Engineering Optimization 43:77-96. doi:10.1061/(ASCE)ST.1943-541X.0000270

[28]. Schiffmann J, Favrat D (2010) Integrated Design and Optimization of Gas Bearing Supported Rotors. 
International Journal of Advances in Engineering \& Technology, April, 2020.

Journal of Mechanical Design 132:51-62. doi: 10.1115/1.4001381

[29]. Soylemezoglu A, Jagannathan S, Saygin C (2010) Mahalanobis Taguchi System (MTS) as a Prognostics Tool for Rolling Element Bearing Failures. Journal of Manufacturing Science and Engineering 132:45-57. doi:10.1115/1.4002545

\section{AUTHORS BiograPHY}

Huseynov Hasan, 1944 year of birth, Doctor of Engineering, professor, manager of department "Technological complexes and special technique" Technical University of Azerbaijan, author of 180 articles, 3 monographs, 4 inventions, 10 textbooks, Honored worker of science. 